\title{
Challenging limitations for achieving decentralization in terms of participatory planning in developing countries, case study: Egypt
}

\author{
A. A. A. M. Ibrahim \\ Department of Architecture, Faculty of Engineering, \\ Cairo University, Egypt
}

\begin{abstract}
Local governments, upon new roles and responsibilities regarding decentralization for achieving democracy, called for participatory planning and participatory budgeting approaches. However, many developing countries suffer from challenging limitations imposed by their local development laws. In this respect, the paper aims at elaborating a coherent understanding of the current process of governance in Egypt as one of the developing countries, in an attempt to identify the different roles of all stakeholders to enable determining the most appropriate intervention, and capacity building programs to achieve the decentralization. This would be presented through a precise analysis for the institutional framework, the planning and budgeting process in view of the strategic regional and local plans that are prepared for these levels, and the local participation of citizens, on application on Ismailia Governorate, as a pilot study. Accordingly, the paper comes out with results mapping out the technical challenges involved with the current system of planning and budgeting, together with analyzing the institutional changes that guarantee the integration of community participation.
\end{abstract}

Keywords: decentralization, participatory planning, capacity building, institutional framework, community participation. 


\section{Introduction}

Given the increased rates of urbanisation in developing countries, especially Egypt, tremendous challenges have been imposed on local governments as well as the communities to improve their managerial capacities to cope with the increasing dynamics and uncertainties derived from urban development. To address these challenges effectively, local governments have been addressing decentralization as a tool for achieving democracy, through the strategic urban management, participatory planning and budgeting to turn the whole planning process into an operationally workable framework.

Therefore, the aim of this paper is to apprehend the current system of planning and budgeting and to map out the process which currently takes place on the level of the governorate, Markaz and villages/cities in Egypt, taking Ismailia Governorate as a case study. These processes were compared to those according to the law of local development in Egypt. This has enabled pointing out the mismatches to clarify the technical and institutional challenges for the implementation of decentralization through the application of the different participatory approaches, and for ameliorating the institutional framework by changing laws and emphasizing the required capacity building for all stakeholders in all planning levels.

\section{Theoretical background}

\subsection{Decentralization and its significance}

Over the past two decades decentralization has become one of the broadest movements, and most debated policy issues, in the world of development. Manor [1]. Decentralization makes government more responsive to local needs by 'tailoring levels of consumption to the preferences of smaller, more homogeneous groups (Shah [2], Wallis and Oates [3], World Bank [4], UNDP [5]). Sustainable development is made possible by "the effective decentralization of responsibilities, policy management, decision-making authority and sufficient resources, including revenue collection authority, to local authorities, closest to, and most representative of, their constituencies" (United Cities and Local Government [6]). For a sample of 80 countries, Huther and Shah [7] find positive correlations between decentralization and indices of political participation, social development, a quality index of economic management, and an overall quality of government index. However, to achieve decentralization, it is vital to go through all the concepts related to strategic, participatory and participatory budgeting concepts.

\subsection{Participatory and strategic planning concepts}

Participatory and strategic preparation of a general planning scheme has continued to take place worldwide and has been reported by many researchers including Healey [8], Innes [9], Ogu [10], and Steinberg and Sara [11]. The 
reportage reveals that participatory and strategic planning has replaced technocratic and comprehensive planning in terms of concepts and approaches to preparing and executing general planning schemes in several cities worldwide (Halla [12]).

However, it should be clearly stated that, it is difficult for urban management to succeed if it is to operate within a rigid statutory framework (Wong et al. [13]). Clarke [14] suggests: 'Traditional master plans have been mainly static in nature, attuned to a scenario of slow urban growth, rapid population growth, lack of infrastructure and services, and shortages of funds and staff in a developing country city, require a more dynamic planning process.' Rondinelli [15] also suggests an adaptive approach based on the concept of strategic planning should be explored to cope with, and to direct, the changing conditions under which development activities must be implemented. Rakodi [16] reinforces these propositions and suggests that the quality of urban planning and management should be improved by a stronger conceptualisation, by moving away from inflexible blueprint plans towards a combination of strategic and detailed action plans and programmes.

As for the strategic planning itself, it is widely defined as a continuous and systematic process during which planning, implementation, monitoring and evaluation are involved to achieve objectives, which emphasises the importance of getting the key stakeholders involved (Wong et al. [13]). This is directly correlated with all participatory approaches concepts. Accordingly, it is important to understand why participation itself is crucial. Most arguments in support of participation portray it as a means of improving both the performance and accountability of a bureaucracy that is outdated, unrepresentative, and underperforming (Barber [17], King et al. [18]).These arguments appear particularly relevant for developing countries. The literature on participation catalogues the virtues of civil society and public deliberation of issues (Cooper [19], Crosby et al. [20], Fox and Miller [21], Frederickson [22], Habermas [23], Putnam [24], Stivers [25]). A result is an increased call for direct citizen participation in public decision making (King et al. [18]).

Among the most effective approaches related to that issue is the participatory budgeting approach. It is a decision-making process through which citizens deliberate and negotiate over the distribution of public resources. The enhanced transparency and accountability that participatory budgeting creates can help reduce government inefficiency and curb clientelism, patronage, and corruption (The World Bank [26]).

\section{Analysis for the current planning and budgeting processes in Egypt}

The aim of this section is to apprehend the existing situation in Egypt, taking Ismailia Governorate as a case study, through a clear analysis for the current situation concerning the institutional framework, the developed visions and budgets for Markazs and Governorates, the planning process in view of the strategic regional and local plans that are prepared by the General Organization 
for Physical Planning in Egypt (GOPP), the budgeting process and the local participation of recipients of the services. All these points would be analyzed and then compared with that stated by the Law of Local Development. This is an attempt to specify the main problems and defects existing in the overall governmental system. This is achieved through specialists' analytical survey on all decision-making levels and interviews with the different stakeholders including the staff in the Governorate General Secretary, the planning and follow-up administration, the urban planning administration, the village development administration, urban planning of the villages committee in the Local Executive Council (LEC), the planning and budgeting committee, all interviewed on the Governorate, district, and village levels, with a number of community leaders, and local citizens.

\subsection{Current situation analysis}

\subsubsection{Brief analysis of the institutional framework}

It is crucial to completely apprehend the governmental framework on the administrative level and also map the relation between different administrations and departments, on the strategic planning and budgeting level in respect to the LPC (Local Popular Councils) and the LEC (Local Executive Council) structures. There are five prototype cells or units of public councils repeated along the hierarchal organization of the governorate. This illustrates the members of the LPC component on each level: the governorate, the "Markaz", the city, the district (hay) and the village. The three effective of which is first that at the village level (Wehda Mahalia). They identify the requirements and needed projects after consultation with the public and community leader. The second is at the "Markaz" level which collects all the proposed plans, and discuss/communicate them again in order to reshape the projects in the light of other interventions in adjacent areas or at the "Markaz" level in general. The third is at the Governorate level in which final list of plans and budgets are elevated to be discussed and refined in the light of a strategic vision.

\subsubsection{Planning and budgeting process mechanism}

The budgeting process in Ismailia governorate mainly begins with the main unified plan coming from the People's Assembly Parliament and distributed on the governorates, with specified amount of funds. This plan deals only with five main sectors which include: Roads, electricity (light poles), environment enhancement, supporting local unit of villages, and finally security, extinguishment unit, and traffic.

The "Planning and Follow-up Administration" (PFA) in Ismailia Markaz requests from the head of each village (or city) to communicate with their community representatives in the LPC to present their projects' proposals and needs (i.e. roads pavement, cleaning tools needed, light poles,.....etc), together with their priorities list. The PFA delivers these standard forms that the head of the village/city finally fills according to the meetings conducted and communications with the community representatives; then the filled forms get 
delivered back to PFA at the "Markaz" level, and this takes place for the five "Markazs" constituting Ismailia.

The PFA in Ismailia "Markaz" should have all these forms delivered to the LPC at the "Markaz" level, and reviewed by the planning and budgeting committee in this level, then to the local popular council at the governorate level, finally up to the Planning and Follow-up Administration at the governorate bureau. During the process of identifying the required projects/interventions and prioritizing them, it is possible on any levels, for the LPC to revise, modify or enhance the list of projects and their priorities. All these forms after being approved at the governorate level, are transformed up to the Ministry of the Local Development (MoLD) and the economic development units at the Ministry of Finance (MoF).

However, there are other main stakeholders who play very important roles in the planning and budgeting process mechanism; they are represented by the village development administration, the urban planning committee, the local citizens' participation, and finally the community leaders.

The Village Development Administration arranges meetings with three main stakeholders' categories including the youth, women and elderly representatives. They mainly discuss the projects and priorities of the youth and the women with the third one and accordingly make decisions. They give priority to the less developed locations regardless any developmental views or strategic plans or scientific methods. These priorities are registered in a formal report signed by all the LPC and LEC members, the normal leaderships and finally the head of the village who does not have a true effective authority more than signing the report. The priorities' lists developed by the LPCs at the village level are sent to the urban planning unit at the LEC at the district level, in which the projects, especially the roads, are to be allocated on maps to test their validity, determine the land properties in which they pass, and give priorities to paving uncompleted part, or short distances, or even linking paved roads together. However, community leaders have emphasized the fact that the planning process executed and officially taking place by the PFA with all its levels are completely isolated from all the small villages and their real needs.

\subsubsection{Budget allocation and distribution}

The funds approved by the Ministry of the Local Development (MoLD) and the economic development units at the Ministry of Finance (MoF) are finalized and re-allocated to the Planning and Follow-up Administration (PFA) at the governorate level, then the funds are distributed as per the following percentages: $10 \%$ of the funds for the main capital city (Ismailia city and 3 main urban zones (Ahyaa), 30\% of the funds are for the common projects between "Markazs", $60 \%$ of the funds are for the "Markazs" (half for the common projects between the villages and the other half is for the villages).

\subsubsection{Coordination between stakeholders}

It is vitally important to highlight how the co-ordination with the stakeholders takes place with respect to the local development projects, herein by referred to as internal co-ordination, and the line ministries projects, which formulates the 
external co-ordination between the governmental structure and the related ministries. First, for the internal coordination, within the different players in the planning and budgeting process, there is a lack of coordination and communication, even at the very basic level of delivering and sharing the plans/projects form. It is extremely obvious that there is absolutely no coordination between the line ministries plans and the local government plans, each authority is functioning in isolation of all the other authorities planning unit. The popular councils can only make proposals about their needs for schools, health units, hospitals ... and other services and infrastructure that are delivered afterwards to the related ministry through the governorate. However, these ministries operate on different level and may or may not respond to these requests.

\section{Role of the strategic planning in the planning and budgeting process}

The role of the strategic planning should be explained with respect to main five stakeholders. First, the urban planning administration at the governorate level, its main tasks include the follow-up of all the planning works, supervision on land properties, boundaries and divisions, revising the master plans of the unplanned areas, co-ordination between the different stakeholders, and the new regional proposed projects,... and other spatial dimension of interventions. This means that strategic planning does not enter into any of its scope of works. From the field visits, it was evidently clear that there is no connection between the local development plans approved by all levels of the Planning and Follow-up Administration (PFA) and the urban plans proposed by the GOPP for the different villages and the cities. There is another very important problem, although the GOPP has completely finished the master plans for all the villages in Ismailia district and Ismailia city, none of these works have reached the urban planning administration with all its levels. To sum up, there isn't any kind of coordination or communication between the GOPP, their works, and any of the staff of the urban planning administration in Ismailia governorate with all its levels. The GOPP with all their proposed plans are completely isolated from the local normal stakeholders in the governorate and away from reality and real people needs. However, the staff in this administration is relatively aware of strategic planning main concepts, but of course ignore everything about its mechanism, implementation methods, criteria......etc, and all embedded details. Second, the urban planning administration at the markaz level reviews the priorities of the projects sent from the villages LPC through the village development administration. It is worth mentioning that it performs jobs strictly limited to allocating the projects in their most suitable locations according to individual and personal experiences and regardless any regional views or strategic plans. Moreover, most of the staff in this unit is assigned to jobs regardless their major specialization. Third, the planning and follow-up administration is strictly committed to receiving the projects priorities lists and forms, then allocating and distributing the available funds according to the 
number of population. This happens in complete ignorance of any strategic or regional plans proposed by any governmental or non-governmental authorities. Fourth, the village development administration, in which the process of determining the projects' priorities, and their allocation approval almost depend on the personal skills and the informal relationships between the general manger of the village development administration with all their staff and the members of the LPC and the LEC together with the normal leaderships. The staff here also ignores everything about maps and strategic planning concepts. Finally, the community leaders originally suffer from being unheard from all their representatives at the LPC. Accordingly, they are completely isolated from any strategic urban plans formulated by the GOPP or any of the authorities in the urban planning administration with all its levels.

\section{Analytical comparison for the planning and budgeting framework as per stakeholders versus local development law}

\subsection{Institutional framework}

The institutional framework constitutes many organization levels. However, the stakeholders' discussion facilitated the sketching of more simple organization charts. It was clear that many stakeholders lack complete understanding of the structures, elections, periods, and hierarchical organizations for the LPCs and the LECs.

\subsection{Planning and budgeting process}

\subsubsection{Planning and budgeting process mechanism}

The planning and budgeting mechanism according to the planning and follow-up unit was almost the same as that stated by the law. However, other stakeholders have emphasized the fact that the planning and budgeting process mechanism only takes the legal form, and implements all the procedures stated by the law theoretically only. This is apparently clear from the fact that the planning and follow-up unit might sometimes ignore the approval of the LPC at the markaz level, and shifts it directly from the village level to the governorate level. Another fact is that the projects priorities are mainly settled down through the personal skills and relationships of the village development administration staff, and the limited technical skills of the urban planning committee at the LEC at the markaz level regardless the integration with the Supreme committee of regional planning clearly stated by the law. In addition, the community leaders emphasize the fact that they are not involved by any mean in making the lists of the required projects or prioritizing them.

\subsubsection{Budget allocation and distribution}

The budget allocation and distribution is executed according to the percentages stated by the law. However, the criteria of the internal distribution among 
villages is limited to one issue, which is the number of population, although there should be other criteria taken into consideration including the areas, distances, developmental levels, and uncompleted projects.

\subsubsection{Coordination between stakeholders}

First, as for the internal co-ordination, the law clearly states the vitality of the unity and harmony between all stakeholders in the governorate, and what happens is exactly the opposite. Every administration just performs its jobs and makes sure it follows legal procedures, regardless any other lower or higher level needs. This is definitely clear in shifting the projects lists from village to governorate levels, and in the primitive role played by the urban planning administration in guiding the required projects and prioritizing them. Concerning the external co-ordination, although the co-ordination with all the ministries is clearly emphasized by the law concerning the integration between their developmental plans and the required projects' lists, none of them refer to any LPC or LEC authorities, when it comes to actual execution of the projects.

\subsection{Role of strategic planning in the planning and budgeting process}

The law clearly states that all the projects requested should be consistent with the regional developmental plans prepared by the Supreme council of regional planning and other planning authorities. However, what happens is that the GOPP for example have finalized the master plans for the villages and the cities without making any attempt to give it to the urban planning authorities in the governorate except recently to the village level only. These were limited to the urban boundaries and services maps, and which proved to be far from reality. Moreover, the urban planning authorities in the governorate in all its levels are not involved by any means, in the process of determining the required projects or prioritizing them except by minor modifications at the markaz level. Therefore, although the law does not clearly refer to certain strategic planning approaches to be followed, it refers to the importance of integrating these projects with the whole regional view, the fact that is completely away from reality.

\section{Deduced problems}

\subsection{Problems regarding achieving strategic planning}

These include many points that can be listed as follows: 1. Insufficient funds, as they do not cover people needs, and this is because the villages and cities are very much under developed and the required intervention projects are enormous and usually beyond the typically allocated budget. 2. "Markaz" level not fully involved, as interventions and project plans is transformed from village/city level up (sometimes) doesn't recognize the "Markaz level". 3. The process of selecting representatives of residents or candidates to make critical decision about development plan is not necessarily a transparent and clear one, and does not always lead to the appropriate candidates. 4 . The lack of spatial dimension in projects distribution is clear, and therefore the proposed projects may be situated 
in areas that affect its functioning and serviceability. 5. Ineffectual head of cities and villages. This certainly wastes a lot of resources and lead to making wrong decisions 6. Lack of coordinated projects. Strategic planning for villages/cities requires high level of coordination and consideration on a larger scale. Currently there is not any sort of coordination between the proposed interventions neither in the same village/city nor between neighbouring villages/cities. 7. Lack of a monitoring and evaluation system. 8. Personal skills and relationships are the main criteria for selecting the projects priorities. 9. Lack of experienced specialized engineers in the urban planning units on all levels.10. Lack of coordination between the Supreme Council of Regional planning and GOPP and all the LPCS on all levels. 11. Small village units (following the wehda mahalia) are completely isolated from the local development plans formulated by their LPC. 13. Other strategic planning issues including: incomplete projects have no priority in the up-coming plan, and lack of integration between local plan and ministries plans. Moreover, there are certain doubts about possibility to shift decentralization from central government to the governorate level only.

\subsection{Problems regarding achieving decentralization}

These can be summarized in the following points: 1. It became an inherited culture to have a lack of trust between popular councils and execution bodies in the local governorate level. 2. The communication channels between the central government and the local government requires more improvement, transparency and to be more frequent. It is crucial to have a dynamic system to share, transform, update and modify the budgeting plan. 3. There is no common agreement upon organisation chart and the lack of extremely clear scope of work for individual positions in the process allow for overlap in activities in addition to gaps in the process that is not covered. Another crucial challenge is that there is no solid agreement about the terms and conditions of planning and budgeting. 4. Complexity of the decentralization project executers. It is obvious that the decentralization programme in Egypt involves different setups of projects that include (different relevant ministries as well as international organizations such as USAID, UNDP and UN-Habitat). It is crucial to identify and clarify the roles each group is playing in order to avoid dropped tasks or overlapping activities. 5 . Criteria of distribution of funds ignores, many factors that has to do with the success of the project and its serviceability; the size, in terms of population or area, are not the only factors that should be considered while allocating funds, other criteria such as level of development, size of project, impact of intervention, need of community...etc) are all factors that shall be part of the funds distribution criteria. 6. The process of planning and budgeting does not always proceed in this recognized manner as there are sometimes instructions from higher authorities to override some decisions, or sometimes there is a need to speed up certain projects (giving priority due to external factors) and this affects the overall progress of other projects. 7 . In addition to the incompetency form city/village mayors, and the bad representation of residents, there is also an unaccepted level of corruption at the lower level especially the villages. 


\section{Recommendations}

The complexity of the decentralization process makes it a challenge to identify specifically the areas of intervention in order to guarantee sustainable and effective improvement in the process. However, based on the above analysis, the paper has come to certain recommendations, which include the following.

First, the recommendations related to strategic planning include the introduction of the strategic planning concept in simple and understandable manners, increasing the available funds to match with the real needs of people and develop strategic plans in the light of availability of these resources, involving all stakeholders on all levels in the strategic planning process, assuring that strategic plans are developed with people in a participatory manner through activation of community sessions and institutionalizing the transformation of local needs through LPC to executive bodies, incorporating urban planners in each engineering department in the local government level, capacity building through provisions of training to candidates in positions of making decisions about development plan (i.e. village/city mayor, head of technical department,...etc)., and finally increasing awareness about the importance of participation among the residents on all levels.

Second, as for the recommendations related to decentralization, they include promoting transparency to strengthen the relation between local government and LPC, redefining the roles and responsibilities of different stakeholders, improving the communication mechanisms between the different players vertically, between the governorate, "Markaz" and village/city level; and horizontally among the same level but in neighbouring villages, developing coherent and realistic database in order to help the decision making process in regards to the intervention plans and their level of effectiveness, and finally, developing systems that matches as much with the current law and channelling the modifications, as much as possible, within the current legal framework.

\section{Conclusion}

In view of Egypt's plans to implement decentralization and modify the local development law in an attempt to contribute to effective local village/city development by supporting local stakeholders through strategic and participatory planning approaches, it was crucial to apprehend all the current planning and budgeting processes on all village, quarter, city, district (markaz), and governorate levels. Therefore, this paper has presented a thorough analysis for the current situation regarding these processes, which was then compared to the existing local development law to identify points of weakness and challenges, on application on Ismailia Governorate.

The paper has come up with the fact that all these processes are still influenced by the idea of central planning and characterised by inflexibility, inadequate responsiveness and lack of representative public participation, a shift of the existing management approach to strategic management is essential, given that it can provide urban management practitioners with a way to enhance 
capacities in handling changes and volatility. Therefore, the final output of the paper was in the form of recommendations regarding both the strategic planning and decentralization approaches implementation in Egypt. They generally addressed the vital need for the capacity building, revisiting the institutional framework, and finally decentralizing the resources to allow the local government to control developing the villages/cities with minimum intervention from the central government.

\section{Acknowledgements}

I would like to thank Eng. Amir Gohar, for being a very cooperative team mate in processing the report about Ismailia, upon which this paper is based, as part of consultancy tasks in the Strategic National Development Support Project with the UN HABITAT, in Cairo.

\section{References}

[1] Manor, J., Lecture given at Technical Consultation on Decentralization for Rural Development, Rome, 16-18 December, 1997.

[2] Shah, A., Balance, Accountability and Responsiveness: Lessons about Decentralization, World Bank, Washington DC Policy, research working paper 2021, 1998.

[3] Wallis, J.J., Oates, W.E., Decentralization in the Public Sector: An Empirical Study of State and Local Government, In: Rosen, H.S. (Ed.), Fiscal Federalism: Quantitative Studies, University of Chicago Press, Chicago, 1988.

[4] World Bank, World Development Report, Infrastructure for Development, Oxford University Press, New York, 1994.

[5] United Nations Development Program (UNDP), 1993. Informe Sobre Desarrollo Humano, CIDEAL, Madrid, 1993.

[6] United Cities and Local Government, 2007, Decentralization and Local Democracy in the World, First Global Report, the Research Network on Local Government in Europe (GRALE), www.cities-localgovernments.org

[7] Huther, J., Shah, A., Applying a Simple Measure of Good Governance to the Debate on Fiscal Decentralization, http://info.worldbank.org/ etools/docs/library/128808.pdf,1998.

[8] Healey, P. (1994). Planning through debate: The communicative turn in planning theory, Town Planning Review, 63(2), pp.143-162, 1994

[9] Innes, J., Planning through consensus building: A new view of the comprehensive planning ideal. Journal of the American Planning Association, 62(4), pp. 460-472, 1996.

[10] Ogu, V., Stakeholders' partnership approach to infrastructure provision and management in developing world cities: Lessons from the sustainable Ibadan project, Habitat International, 24(4), pp. 517-533, 2000. 
[11] Steinberg, F., \& Sara, L., The Peru urban management programme: Linking capacity building with local realities, Habitat International, 24(4), pp.417-431, 2000.

[12] Halla F., Critical elements in sustaining participatory planning: Bagamoyo strategic urban development planning framework in Tanzania, Habitat International, 29 (1), pp. 137-16, 2005.

[13] Wong S.W., Tang B., Horen B., Strategic urban management in China: A case study of Guangzhou Development District, Habitat International, 30 (1), pp. 645-667, 2006.

[14] Clarke, G., Towards appropriate forms of urban spatial planning, Habitat International, 16(2), pp.149-165, 1992.

[15] Rondinelli, D., Development Projects as Policy Experiments: An Adaptive Approach to Development Administration, London: Routledge, 1993.

[16] Rakodi, C., Forget planning, put politics first? Priorities for urban management in developing countries, International Journal of Applied Earth Observation and Geo information, 3(3), pp. 209-223, 2001.

[17] Barber, Benjamin, Strong Democracy: Participatory Politics for a New Age. Berkeley: University of California Press, 1986.

[18] King, Cheryl Simrell, K. M. Feltey, and B. O’Neill Susel, The Question of Participation: Toward Authentic Public Participation in Public Administration. Public Administration Review, 58 (4): pp. 317-25, 1998.

[19] Cooper, Terry L., "Citizenship and Professionalism in Public Administration.” Public Administration Review 44 (Special Issue): pp. 143 49, 1984.

[20] Crosby N., Janet J., Kelly, and Schafer P., "Citizen Panels: A New Approach to Citizen Participation." Public Administration Review, 46 (2): pp. 170-78, 1986.

[21] Fox, Charles J., and Miller Hugh T., Postmodern Public Administration: Toward Discourse, Thousand Oaks, CA: Sage Publications, 1996.

[22] Frederickson, H. George, 1982. "The Recovery of Civism in Public Administration", Public Administration Review 42 (6): pp. 501-08, 1982.

[23] Habermas, Jurgen., The Structural Transformation of the Public Sphere. Cambridge, MA: MIT Press, 1989.

[24] Putnam, Robert. 1993, Making Democracy Work: Civic Traditions in Modern Italy. Princeton, NJ: Princeton University Press, 1993.

[25] Stivers C., "Citizenship Ethics in Public Administration." In Handbook of Administrative Ethics, ed. Terry L. Cooper, 435-55. New York: Marcel Dekker, 1994.

[26] The World Bank, Participatory Budgeting, Public Sector Governance and Accountability Series, ed. Shah A., Washington, D.C., 2007. 